\title{
Trends and opportunities in food pathogen detection
}

\author{
S. R. Nugen • A. J. Baeumner
}

Published online: 18 March 2008

(C) Springer-Verlag 2008

Despite the recent advances in food pathogen detection, there still exist many challenges and opportunities to improve the current technology. Techniques such as immunomagnetic separation (IMS) and polymerase chain reaction (PCR) have paved the way for rapid and sensitive detection of foodborne pathogens, and advances in nanobiotechnology have allowed for miniaturization of devices. Collaborations between workers in the fields of engineering, nanotechnology and food science have introduced new lab-on-a-chip technologies permitting development of portable, hand-held biosensors for food pathogen detection. This report highlights examples within the current state of the art, and emphasizes areas in which further research is needed.

In 1999 it was estimated that foodborne pathogens were responsible for 76 million illnesses annually, resulting in 5,000 deaths [1]. This report identified Salmonella, Listeria and Toxoplasma as the major causative agents, being responsible for 1,500 of the reported deaths. Data published in 2006 by the CDC suggested that infections due to Yersinia, Shigella, Listeria, Campylobacter, Escherichia coli O157:H7 and Salmonella have decreased dramatically, while infections due to Vibrio have increased [2]. A more recent report indicated similar findings, with a decrease in Yersinia, Shigella, Listeria and Campylobacter cases, and again a significant increase in Vibrio infections [3]. The declining rates of infection due to Listeria monocytogenes and E. coli O157:H7 are likely a result of increased awareness. The FDA, USDA and EU have all implemented a zero-tolerance rule for L. monocytogenes in ready-to-eat

S. R. Nugen · A. J. Baeumner $(\bowtie)$

Department of Biological and Environmental Engineering,

Cornell University,

318 Riley-Robb Hall,

Ithaca, NY 14853, USA

e-mail: ajb23@cornell.edu
(RTE) foods. Similarly, the USDA's Food Safety and Inspection Service (USDA-FSIS) has declared E. coli O157:H7 in raw ground beef to be an adulterant and therefore unfit for human consumption. Food safety practices have vastly improved in the processing environment as a result of these regulatory actions, as evidenced by the decreasing rates of infection by both Listeria and E. coli O157:H7. However, of the 121 foodborne outbreaks reported through FoodNet in 2005, almost half $(49 \%)$ of the reported cases were attributed to noroviruses, and the number of Vibrio infections is on the rise [2]. Therefore, while the "hot" organism may change and while food safety practices are improving, there remains a growing need for enhanced means of food pathogen detection.

In addition to the health risk associated with contaminated foods, there is the often devastating economic impact to the food producer. A 2007 recall of $21.7 \times 10^{6} \mathrm{lb}$ of ground beef owing to contamination with E. coli $\mathrm{O} 157: \mathrm{H} 7$ resulted in the Topps Meat Company going out of business after 67 years of operation. Indeed, the consolidation of food producers in the USA means that the larger companies have a greater responsibility toward protecting the food supply. Coast-to-coast and international distribution by these megaprocessing plants puts potential outbreaks on a national and international scale. Increasing automation in food processing facilities increases the risk of contamination by environmental sources following heat treatment, which is a critical concern especially for RTE products. Therefore, monitoring of pathogen counts on processing surfaces is critical in maintaining low or zero counts in food products.

The costs of warehousing along with the potential costs of product recalls have potentially made on-site pathogen testing economically advantageous. Faster results would mean that products could go to market earlier. Several companies such as Marshfield Food Safety and IEH now 
offer on-site testing services for food production facilities. The latter can equip a production facility with modular laboratories that can be brought in, providing faster turnaround results. These needs stem from the increasing number of microbiological tests commissioned for analysis each week. A 2000 study estimated the number of weekly tests commissioned per dairy plant to be 636 , followed closely by 444 weekly microbiological tests from processed-food plants [4].

\section{Biosensors, immunoassays and molecular biological techniques}

There have been many sensors developed for the detection of foodborne pathogens with the goal to overcome problems associated with traditional microbiological detection techniques such as being time- and labor-intensive [5]. In fact, biosensor advancements have greatly improved our ability to detect minute quantities of analytes as research into biosensors has mainly focused on detection platforms with very low detection limits [6-8]. It has been estimated that $38 \%$ of reported pathogen biosensors in the past 20 years were designed for the food industry [9]. Biosensors are a broad category of detection devices. Some biosensors are designed to be used on a benchtop such as the Biacore ${ }^{\mathrm{TM}}$ system. This system uses surface plasmon resonance to detect binding activities to immobilized antibodies on the reaction surface and has been shown to have detection limits in the nanomolar range. One study found that E. coli and Salmonella could be detected in skim milk with limits of detection of 25 and $23 \mathrm{CFU} / \mathrm{mL}$, respectively [10]. The assay had a run time of less than $1 \mathrm{~h}$. Other detection methods such as antibody-functionalized microcantilevers have the ability to detect the mass of a single virus [11]. The sensitivity of the cantilever is on the scale of attograms. Although this sensitivity is extremely low, the cantilever still needs to be integrated into a device that is practical for detection from a food matrix. Other biosensor formats such as the lateral flow assay or the dipstick assay offer ease of use while providing sensitive results [12].

Rapid methods of pathogen testing have been gaining increasing interest in the food industry. These methods include antibody-based assays, genetic amplification methods and newer sensor development. Traditional plating methods following enrichment can take days to yield results, while newer rapid methods require hours [9]. Genetic amplification methods such as the PCR and nucleic acid sequence based amplification (NASBA) have made it possible to significantly reduce assay times while maintaining a high level of sensitivity and specificity. These methods are also able to distinguish closely related species which most antibody tests could not. Nevertheless, such amplification tools are currently used only as a screening technique prior to traditional culturing methods. This is due to the fact that government recalls are not based on PCR assays alone. PCR assays which use DNA as a target are usually not quantitative with regard to viable organisms. Similar issues of cell viability can exist with the use of antibody detection. The issue of viability can be overcome by using RNA targets which are rapidly degraded following cell death [13].

The BAX ${ }^{\circledR}$ system by DuPont uses automated PCR and fluorescence detection to analyze food and environmental products for a number of food pathogens such as Campylobacter, E. coli, Listeria and Salmonella. The automation of PCR for up to 96 samples along with integrated detection makes this a fast and convenient system for pathogen screening. Other automated systems such as the Tecra ${ }^{\circledR}$ UniqueTM from Biotrace International offer automated "walk away" immunoassays. In a recent study, the BAX ${ }^{\circledR}$ and Tecra ${ }^{\circledR}$ systems were used to analyze Salmonella spiked raw and RTE foods, and these rapid methods were found to provide results similar to those from traditional culture methods. When a large background flora was added to the samples, false-negative results were obtained with both the Tecra ${ }^{\circledR}$ and the culture methods, while the PCR-based BAX ${ }^{\circledR}$ system was able to provide an identification [14]. The use of these rapid methods could therefore reduce the assay time from a few days to $24 \mathrm{~h}$ including enrichment time. The automation also reduces the possibility of user error. The drawback of such systems is the initial price of the instrument. Thus, newer generations

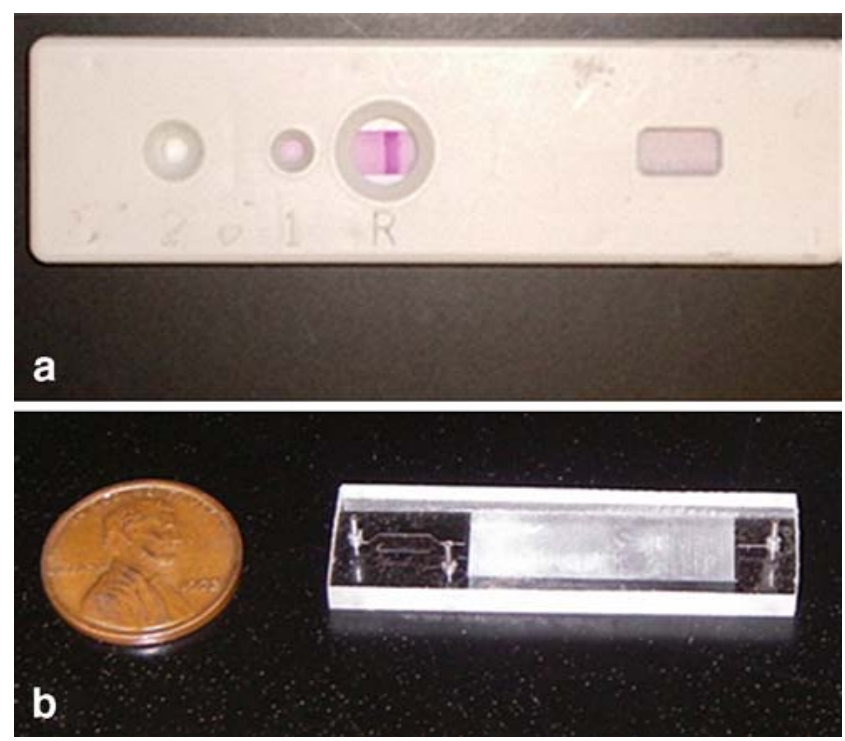

Fig. 1 Biosensors have a promising future in food pathogen detection. Pictured are two formats of biosensors being developed for the food industry. a lateral flow assays offer low cost, convenience and ease of use, while $\mathbf{b}$ emerging lab-on-a-chip formats can offer automation and low detection limits 
of biosensors are designed to offer similar sensitivities while decreasing detection times, increasing portability or reducing the limit of detection (Fig. 1).

\section{Sample preparation}

Many of the sensors presented detect analytes in a small and relatively clean sample; however, there exist opportunities for improvement of sample preparation. Biosensor researchers are increasingly realizing the limitations of sensors developed in buffer solutions [15]. Genetic amplification steps such as PCR and NASBA are sensitive to inhibitors and therefore require extensive sample preparation and cleanup. This is not always an easy task with complex food systems such as peanut butter or RTE puddings which make isolation of the pathogens from the food matrix difficult. The time required to prepare the sample could possibly take far longer than the biosensor detection time. As detection systems get smaller and sample sizes decrease, a concentration step becomes necessary. IMS uses antibodies immobilized on micron-scale paramagnetic beads to capture and isolate analytes from an aqueous food system. A comparison of IMS with standard culture methods for the detection of Listeria in environmental samples found IMS to be as sensitive while reducing the detection time [16]. IMS of L. monocytegenes on ham samples had a detection limit of $1.1 \times 100 \mathrm{CFU} / \mathrm{g}$ using a 25-g sample [17]. However, antibodies capable of efficiently binding the analyte at low concentrations are required for the IMS step to become useful.

Automated systems using immunomagnetic beads such as Pathatrix (Matrix MicroScience) have shown promise for isolating microorganisms from food systems such as fresh salad [18], ground beef [19], potato salad and mashed potatoes [20]. This system offers the advantage of a large 250-mL sample size. Other methods such as buoyant density gradiant centrifugation have also been successfully used to separate bacteria from a food matrix prior to PCR [21].

Pre-enrichment has been a reliable technique used to increase the number of microorganisms in a sample, resulting in easier detection [22]. It is used in combination with many simple lateral flow assays for food pathogen detection. However, this step makes quantification of the original bacterial load impossible and is often the most time-consuming part of a microbial assay.

\section{Outlook}

The market potential for food pathogen detection was estimated to be $\$ 150$ million per year [4]. This study estimated that 144.3 million microbiological tests were conducted in the food industry in 1999. The majority of these tests came from processed-food plants, followed closely by dairy plants. Of the tests performed, $37 \%$ were for total viable organisms, $31 \%$ for colifom $/ E$. coli, $16 \%$ for yeast and mold, and $16 \%$ for specific pathogens.

Biosensors can also be designed for several applications in the food industry. With many countries refusing to accept the import of genetically modified organism (GMO) food products, there is an additional economic impact to their use. Biosensors can be used to identify GMO products by detecting transgenic genes [23-28]. In addition, biosensors can also be used to detect pesticides and environmental toxins in foods.

As nanobiotechnology progresses, sensors to detect pathogens or their constituents become smaller and more sensitive. Owing to the nature of these nanoscale sensors, the sample size from which the detection is being made is typically a microliter or smaller. Therefore, the challenge for scientists developing detection methods for pathogens in foods is in the sample preparation. Although the sample preparation requirements will vary from one food product to another, research into this step is required to bridge the emerging field of nanosensors with the food industry. The sample preparation will not only depend on the food martix, but on the pathogen as well. Pathogenic viruses, bacteria and parasites might all exist within the same food product. For now, automation using more traditional detection methods such as the $\mathrm{BAX}^{\circledR}$ system is increasing in popularity, and the same will hold true for less expensive and yet more powerful sensors of the future that are integrated with sample preparation. Although the incidences of outbreaks of some pathogens may be declining, this is most likely due to increased testing and awareness. Following the E. coli outbreaks in 2007, the USDA-FSIS announced that it has increased $E$. coli testing in ground beef by $75 \%$. Thus, while the organism with the largest number of diagnosed cases may fluctuate from year to year, the food industry will always be looking for detections system that will help identify all pathogens of concern in its food products.

\section{References}

1. Mead PS, Slutsker L, Dietz V, McCaig LF, Bresee JS, Shapiro C, Griffin PM, Tauxe RV (1999) Emerg Infect Dis 5:607-625

2. Swaminathan B, Gerner-Smidt P (2006) Foodborne Pathog Dis 3:220-221

3. Gerner-Smidt P, Whichard JM (2007) Foodborne Pathog Dis $4: 249-251$

4. Alocilja EC, Radke SM (2003) Biosens Bioelectron 18:841-846

5. Baeumner AJ (2003) Anal Bioanal Chem 377:434-445

6. Nakamura H, Karube I (2003) Anal Bioanal Chem 377:446-468

7. Baeumner AJ, Pretz J, Fang S (2004) Anal Chem 76:888-894 
8. Lei Y, Chen W, Mulchandani A (2006) Anal Chim Acta 568:200-210

9. Lazcka O, Del Campo FJ, Munoz FX (2007) Biosens Bioelectron 22:1205-1217

10. Waswa JW, Debroy C, Irudayaraj J (2006) J Food Process Eng 29:373-385

11. Ilic B, Craighead HG, Krylov S, Senaratne W, Ober C, Neuzil P (2004) J Appl Phys 95:3694-3703

12. Nugen SR, Leonard B, Baeumner AJ (2007) Biosens Bioelectron 22:2442-2448

13. Rauhut R, Klug G (1999) FEMS Microbiol Rev 23:353-370

14. Cheung PY, Kwok KK, Kam KM (2007) J Appl Microbiol 103:219-227

15. Batt CA (2007) Science 316:1579-1580

16. Jackson BJ, Brookins AM, Tetreault D, Costello K (1993) J Rapid Methods Autom Microbiol 2:39-54

17. Hudson JA, Lake MG, Savill P, McCormick RE (2001) J Appl Microbiol 90:614-621

18. Prentice N, Murray JS, Scott MF, Coombs JP, Parton A (2006) J Rapid Methods Autom Microbiol 14:299-308
19. Wu VCH, Gill V, Oberst R, Phebus R, Fung DYC (2004) J Rapid Methods Autom Microbiol 12:57-67

20. Warren BR, Yuk HG, Schneider KR (2006) J Rapid Methods Autom Microbiol 14:309-324

21. Fukushima H, Katsube K, Hata Y, Kishi R, Fujiwara S (2007) Appl Environ Microbiol 73:92-100

22. Jaykus L-A (2003) ASM News 69:341-347

23. Meric B, Kerman K, Marrazza G, Palchetti E, Mascini M, Ozsoz M (2004) Food Control 15:621-626

24. Miraglia M, Berdal KG, Brera C, Corbisier P, Holst-Jensen A, Kok EJ, Marvin HJP, Schimmel H, Rentsch J, van Rie J, Zagon J (2004) Food Chem Toxicol 42:1157-1180

25. Deisingh AK, Badrie N (2005) Food Res Int 38:639-649

26. Kalogianni DP, Koraki T, Christopoulos TK, Ioannou PC (2006) Biosens Bioelectron 21:1069-1076

27. Rossi S, Lesignoli F, Germini A, Faccini A, Sforza S, Corradini R, Marchelli R (2007) J Agric Food Chem 55:2509-2516

28. Liu JF, Xing D, Shen XY, Zhu DB (2004) Biosens Bioelectron 20:436-441 